includirg them in the present series. So far as I know, in two of these four cases the result was successful, whilst in two others the patients succumbed from the consequerces of the operation. I mention this latter fact merely because it will be seen from it that their inclusion in my tables would not have altered the proportion of success. In my own practice radical operation has been carried out in twelve cases ; from 1886 to 1890 by surgical friends of mine, since then by myself. I have felt my way very cautiously, and it will be seen from the table which will follow that in one case only (Case 7) I have deviated from my universal rule-viz., to limit radical operation to cases of purely "intrinsic" malignant disease. In that case the chances appeared so excellent, owing to the easy accessibility, the small size and the pedunculated nature of the new growth, that radical operation seemed not only justified, but plainly indicated. In all the remaining eleven cases, however, the disease was strictly limited to the confines of the larynx proper.

In order to ascertain the proportion of cases suitable in my opinion for radical operation, from the total number observed between 1878 and the present day-viz., 103 -those cases of course will have to be subtracted which I observed from Ostober, 1878, to May, 1886. They number altogether 22 , and must be subdivided into 11 cases of "intrinsic," 7 cases of "extrinsic," and 4 cases of "mixed" malignant disease. From this it follows that from May, 1886, to the present day I have seen in private practice 44 cases of "intrinsic," 31 of "extrinsic," and 6 cases of "mixed" disease, or, altogether, 81 cases. Taking into account the one case of extrinsic disease in which $I$ recommended radical operation, it would follow that in 44 cases of intrinsic disease I only fifteen times recommended radical operations. From these 44, however, one more case has to be subtracted. This is the very extraordinary case referred to in a letter I published in $1887^{10}$ in which, whilst only desiring to remove for microscopic examination a piece of a suspicious warty growth from the vocal cord of a man aged seventy-five years, by sheer good luck I succeeded in removing the whole growth with its base. The disease has not returned. The microscopic examination made by Mr. Shattock showed that we had to do with a most typical cornifying epithelioma. Thus 43 cases only of intrinsic malignant disease remain, in 15 of which radical operation was advised; and this gives as nearly as possible a proportion of 2 to 6 -i.e., a small minority only in which I deemed radical operation advisable. The reasons of $\mathrm{my}$ advising in the majority of cases of intrinsic cancer I have seen, either directly against radical operation or, at any rate, only holding this out as a possibility to be thought of, were of various kinds. In a number of cases the disease, though still confined to the interior of the larynx, was of a very extensive character, and would in all probability have necessitated very serious operations, amounting in a good many instances to total extirpation of the larynx. In other cases the age of the patients was too advanced to justify the performance of a big operation. Again, in other cases there was either long-standing pulmonary, bronchial, or organic heart disease, or the general health had been shattered from other reasons, conditions which seriously militate against the performance of a major operation in the upper air passages. In the two cases in which, in spite of the objections just named, the operation was decided upon (see Cases 6 and 9 in the table), the result, I regret to say, was disastrous. I have never advised radical operation in cases in which the originally intrinsic disease had either passed beyond the confines of the larynx proper or in which it was primarily situated on the posterior surface of the cricoid cartilage, or in which affection of the cervical glands was already present. My reasons for not doing so were and are that in these cases not only must the operation be of a very extensive and most serious character, necessitating often not only the removal of the whole larynx, but also of a considerable portion of the upper part of the oesophagus, but also that it has under such circumstances often been found impossible to complete the operation, owing to the implication of the large vessels and nerves of the neck in the disease, and, finally, because, even if the operation can be completed and the patient recovers from its immediate effects, speedy recurrence is unfortunately too likely to take place. It appears to me that whilst an operation is still so much sub judice as radical operation of any kind in cases of malignatt disease of the larynx, and whilst public opinion, even in the medical profession, is still so divided on the subject it is wiser to at first confine such interference to cases in which a reasonable prospect not only of recovery, but of immunity against recurrence, can be held out, and thas to convince public opinion of the legitimacy and hopefalness of such radical operations. I wish, however, not to be understood, by thus limiting my own practice to the more favourable class of cases, as if I deprecated or condemned the practice of those surgeons who even in more advanced or otherwise apparently less favourable cases have not hesitated to undertake radical operation. The results obtained in a good many of such cases have certainly justified their performance, and it may be hoped that with further advances in technique the general results even in this class of cases will become better than they bave hitherto been. I am, however, in no fear of contradiction if I say that the aim of all surgeons ought to be to perform radical operation at such an early stage of the disease that the operation can be limited to the performance of mere thyrotomy with removal of soft tissues only. shali insist on this point further on more fully, bat consider it right to mention this question already in this connexion, lest I should be thought inimical to bolder procedures than my own.

(To be continued.)

\section{TYPHOID FEVER COMPLICATING PREGNANCY; RECOVERY.}

BY S. A. E. GRIFFITHS, L.R.C.P. LoND., M.R.C.S. ENG。

ON Sept. 24th I was called to see a woman aged twenty-eight years, who was in labour. The pulse was 130 and the temperature $103^{\circ} \mathrm{F}$. She was delivered in about three hours easily and normally of a living child. The placenta came away normally, but there was slight prolapse of the aterus, the pulse and temperature being still about the same. On Sept. 25th and 26th the temperatnre was between $102^{\circ}$ and $103^{\circ}$ in the morning and between $103^{\circ}$ and $104^{\circ}$ in the evening. On the $26 \mathrm{th}$, at about 4 P.M., the patient became maniacal, tossing and throwing herself about the bed, and shouting and singing at the top of her voice. This continued until about 4 o'clock the next morning, the mania lasting just twelve hours. There was no donbt of it being puerperal mania and not delirium, as the temperature was not higher than it had been before, neither had it the character of delirium. The mania passed off, there being no recurrence. I may say that her father has been in a lunatic asylum. I gave her a mixture of potassiam bromide and chloral hydrate, but she took but little, throwing and spitting it about the room. About 2 A.M. I was called up as her friends could do nothing with her. I gave her morphia, placing a tabloid under the tongue, and shortly afterwards. she became quieter. On the 27 th the patient was quiet, the temperature was $104^{\circ}$, and the pulse 130 , very weak. It was difficult to account for the high temperature, pointingstrongly to its being a case of puerperal fever; against this there was the presence of the fever before her confinement. I obtained the following history. On Sept. 14th the woman felt feverish and did not sleep. She bad "shivering fi is" when she got up, had no appetite, and only took a little milk, gruel, and brandy, but no solid food. She said she felt pain at the lower part of the stomach and the limbs and back ached. The urine was thick and high-colonred. The bowels had been loose throughout the week and on Sept. 22nd she had diarrhoea. The patient said labour pains came on on the afternoon of the 23rd, when she had to go to bed and could not get up again. The pregnancy was full term. I diagnosed the case as typhoid fever complicating preenancy, and Messrs. Crew and Burland, who saw the case with me afterwards, were of the same opinion. I may say that almost from the commencement of the illness till the patient was well on the road to recovery I gave a vaginal douche daily, and for the first week twice a day for the first two or three days as a precautionary measure in case of septicæmia, and afterwards because I considered the discharges from a patient in such a condition could hardly be normal. I first of all used perchloride of mercury, but finding it too irritating I changed it for boracic lotion. After a few days spots appeared on the abdomen; the tongue was fairly characteristic; diarrhoea was rather severe at times and had to be checked with opium; the stools were those of typhoid fever. I'he patient complained very much all through the illness of pain in the abdomen, which was worse at one time than another, and as she 
was much affected with flatus I put it down to that. The fever ran a fairly normal course, the temperature never going above $104^{\circ}$. I had the patient sponged with cold water when the temperature was at its height, which was much appreciated. Although she took milk well, she was exceedingly weak. I had to give her brandy from the first in large quantities. Even then the pulse showed signs of failure; at one time it could not bave been less than 140 , at another time it was only jast perceptible. I gave her five minims of tincture of digitalis to each dose, which strengthened the pulse and slowed its action.

Remarks. - I here was a difficulty in diagnosing this case at once as typhoid ferer because of the really great probability of the presence of fever in a puerperal case being of a septic nature. The fact of there being diarrhoa did not help, as it is well known that it is frequent to get severe diarrboa with septicæmia, and that of a typhoid character. In my own mind I did not consider it was septicæmia from the first, and the presence of spots and other symptoms, with eventually the remittent character of the fever and its decline by lysis, clinched the diagnosis.

Irthlingborough.

\section{CASE OF}

PENETRATING WOUND OF ABDOMEN,

WITH PROTRUSION OF INTESTINE AND COMPLETE SEPARATION OF THREE PIECES BY A SUICIDE.

By CEDRIC B. PRALL, M.R.C.S. ENG., L.R.C.P.LoND, SURGEON-LIEUTENANT, INDIAN MEDICAL SERVICE.

THE case reported below is, I think, worthy to be brought before the notice of the profession, as it exemplifies how easily one may be deceived by appearances, and, by not in the first place investigating all the circumstances of a case, how entirely its aspect may be changed and one's prognosis considerably altered.

A syce (native groom), a servant of Colonel Handcock, C.B., Delhi, attempted to commit suicide in the early part of September of this year by stabbing himself in the abdomen. He was immediately brought to the $36 \mathrm{~h}$ Sikhs Hospital, Delhi, which was only a few hundred yards distant from his stables. I was in the hospital at the time and saw him at once. He was a strong, healthy-looking man of about thirty years of age, in a semi-comatose condition; there was a jagged wound of about three inches in length through the entire abdominal wall, reaching inferiorly just below the umbilicus. Through this, tightly constricted, several coils of intestine were protruding; in one coil there was an incised wound about three-quarters of an inch in diameter. There was but little bæmorrhage externally. The man being unable to answer questions I did not make any further inquiries, as perhaps I should have done, but assumed the condition described above to be the sum total of the injuries and immediately commenced to attend to him. With antiseptic precautions I united the intestinal wound in the ordinary way with Lembert's sutures. In commencing to return the gut I noticed there was more blood in the peritoneal cavity than could be accounted for by the injuries already noticed. At this moment a fellow-servant of the patient came up, bringing three pieces of intestine, which he stated the suicide had cut off. The truth of this statement was verified by the cantonment magistrate, who had just come ap, and subsequently by several other witnesses. There were three distinct pieces of small intestine, each about three inches long, with the mesentery attached, and filled with fæoal matter. This, of course, entirely altered the aspect of the case, and I saw at once that it was hopeless. The man's condition was now extremely bad, so I simply washed out the peritoneal cavity, inserted a drainage tube and closed the abdominal wound there had been considerable hæmorrhage into the peritoneal cavity. The man died about an hour afterwards. Assistantsurgeon Mul Chand performed the necropsy during my absence, and found the intestine divided as described.

This case is extraordinary on account of the points mentioned at the beginning, but more so on account of the unusual fortitude and determination shown by the man in himself cutting off the three pieces of gut after protrusion and returning what was left outside. It appears that after separating the intestine he himself returned the remainder, and that during his removal to the hospital a different set of coils protruded and thus gave the appearance described in the first place.

36th Sikhs Camp, Kurnal, India.

\section{S a}

\section{H O S P I T A L P R A C T I CE, B RITISH AND FOREIGN.}

Nulla autem est alia pro certo noscendi via, nisi quamplurimas et morborum et dissectionum historias, tum aliorum tum proprias collectas habere, et inter se comparare.-MokgaGNI De Sed. et Caus. Morb., lib. iv. Procmium.

\section{LONDON HOSPITAL.}

A CASE OF GASTROTOMY AND RETROGRADE DILATATION FOR TRAUMATIC SIRICIURE OF THE GSOPHAGUS; REMARKS.

(Under the care of Mr. Manseld Mouldin.)

THIs is an example of a method of treatment which is applicable in a limited number of cases of simple fibrous stricture of the cesophagus and will probably be new to most of our readers. "As originally proposed and carried out by Loreta, as soon as the stomach has been exposed it is opened, the cardiac orifice is songht for, a dilator guided by the finger is passed through the stomach into the œsophagus and is insinuated into the stricture, and the stricture is at once forcibly dilated. That sufficient has been done is tested by the passage of a bougie from the mouth downwards. The stomach wound is then immediately closed, the abdominal wound sutured, and the operation completed. The other method consists in at first performing gastrotomy - that is, in fixing a piece of the stomach into a wound made in the left epigastric region. The stomach is not usually opened for two or more days, and nothing further is done until a gastrio fistula has been established. When this is attained the stricture is attacked through the fistula, gradually dilated by the passage of various devices from above. When dilatation has sufficiently advanced to permit of the further treatment being carried out from above the gastric fistula is allowed heal or is closed by a plastic operation." 1 This operation was first devised and successiully performed by Professor Loreta of Bologna in 1883.

A woman twenty-six years of age was admitted into the London Hospital on June 11th, 1894, suffering from traumatic stricture of the oesophagus. Five weeks before she had swallowed a teaspoonful of a solution of caustic soda. She was seized at once with intense pain all down the throat and within a few minutes was violently sick; but, probably because it was shortly after a meal and therefore the soda was soon diluted, the stomach did not seem to have sustained much harm and there was little col. lapse. Retching, more or less severe, continued for a week. Then about three weeks after the injury difficulty in swallowing was noted. This continued, rapidly growing worse, until on her admission fluids could only be swallowed in very small quantities and with extreme slowness. A No. 11 cesophageal bougie passed nine inches and a balf (measured from the teeth) and then was stopped abruptly. A No. 7 and a No. 5 passed five inches farther down, but nothing could be passed through into the stomach and no improvement in deglutition followed. The stricture, therefore, was a long one, beginning above the left bronchus, narrowing slowly for about five inches, and then immediately above the cardiac opening contracting so that nothing but fluid could pass through. Gastrotomy was performed on June 20th with the view of dilating the stricture from below; but, though the position of the cardiac orifice cculd be made ont without much difficulty by the forefinger introduced into the stomach, the opening was too firmly contracted to allow the tip to enter and dilate it. The stomach was accordingly sutured to the anterior abdominal wall and a gastric fistula established, so that the patient (who was greatly emaciated) might be adequately fed and that time might be gained for the adoption of other measures. Two attempts were made to carry a silk thread through by means of small shot after the manner recommended by Hagenbach and adopted by Tietz. ${ }^{2}$ In one attempt eight perforated shot (No. 6 size) were nsed, and in the other only one; but although the patient kept them down for tbree days and tried by swallowing small

1 Mr. Kendal Franks, Annals of Surgery, April, 1894, p. 390. 